NBER WORKING PAPER SERIES

\title{
NEAR-RATIONALITY AND INFLATION IN TWO MONETARY REGIMES
}

\author{
Laurence Ball
}

Working Paper 7988

http://www.nber.org/papers/w7988

\section{NATIONAL BUREAU OF ECONOMIC RESEARCH 1050 Massachusetts Avenue \\ Cambridge, MA 02138}

October 2000

I am grateful for research assistance from Qiming Chen, Julie Smith, Martin Sommer, and Rebecca Zarutskie, and for suggestions from Todd Clark, Jeffrey Fuhrer, Mark Gertler, Peter Ireland, N. Gregory Mankiw, Edward Nelson, Adrian Pagan, John Roberts, John Shea, and numerous seminar participants. I completed this paper as a Houblon-Norman Fellow at the Bank of England. The views expressed in this paper are those of the author and not necessarily those of the National Bureau of Economic Research.

(C) 2000 by Laurence Ball. All rights reserved. Short sections of text, not to exceed two paragraphs, may be quoted without explicit permission provided that full credit, including $\mathbb{C}$ notice, is given to the source. 
Near-Rationality and Inflation in Two Monetary Regimes

Laurence Ball

NBER Working Paper No. 7988

October 2000

JEL No. E31

\begin{abstract}
Sticky-price models with rational expectations fail to capture the inertia in U.S. inflation. Models with backward-looking expectations capture current inflation behavior, but are unlikely to fit other monetary regimes. This paper seeks to overcome these problems with a near-rational model of expectations. In the model, agents make univariate forecasts of inflation: they use information on past inflation optimally, but they ignore other variables. The paper tests sticky-price models with near-rational expectations for two periods in U.S. history, the post-1960 period of persistent inflation and the period from 1879 to 1914 , when inflation was not persistent. The models fit the data for both periods; in contrast, both rational-expectations and backward-looking models fail for at least one period.
\end{abstract}

Laurence Ball

Department of Economics

Johns Hopkins University

Baltimore, MD 21218

and NBER

lball@jhu.edu 


\section{INTRODUCTION}

How can we explain the short-run behavior of output and inflation? Since Fischer (1978), many researchers have sought to do so with models that combine nominal price stickiness and rational expectations. Currently, the most popular models of this kind are Taylor's (1980) and Calvo's (1983) models of staggered price adjustment. Unfortunately, recent work shows that these models fail to fit key facts about the macroeconomy. In particular, the models are inconsistent with the inertia in real-world inflation -- the persistent effects of shocks to inflation, and the output costs of reducing inflation (e.g. Fuhrer and Moore, 1995; Roberts, 1998; Mankiw, 2000).

In searching for better models, some authors suggest relaxing the assumption of rational expectations. They argue that some or all agents have "backward-looking" expectations: expected inflation equals past inflation (e.g. Ball, 1991; Roberts, 1997; Rudebusch and Svensson, 1999). Roberts (1998) and Fuhrer (1998) show that the canonical staggered-price-setting model fits the data much better when backward-looking behavior is introduced. However, backward-looking models were rejected in the 1970 s for a good reason: the Lucas (1976) critique. While the models fit the behavior of inflation in the current monetary regime, expectations are likely to change if monetary policy changes. Therefore, backward-looking models produce misleading predictions about the effects of policy shifts. 
Thus researchers face a dilemma: rational-expectations models fail to fit key facts, but backward-looking models are subject to the Lucas critique. This paper looks for a solution to this dilemma. I propose a less-than-fully-rational model of expectations that is applicable to any monetary regime. The deviation from rationality is that agents use only a limited set of information to forecast future variables. Specifically, in forecasting inflation, they use only the past behavior of inflation. They use this univariate information optimally, but they do not use information on other variables, such as output or interest rates. Following Akerlof and Yellen (1985a), I interpret this behavior as a "near-rational" approach to forecasting that reduces the costs of gathering and processing information.

For the postwar United States, my assumption is close to the assumption of backward-looking expectations. For this period, the univariate behavior of inflation is close to a random walk; thus lagged inflation is close to an optimal univariate forecast of inflation. However, my model does not assume that backward-looking expectations are a fixed feature of the economy. In other monetary regimes, the univariate process for inflation can differ greatly from a random walk. In such regimes, expected inflation differs greatly from lagged inflation.

After discussing alternative theories of expectations, I embed the theories in simple sticky-price models and test their implications. Since the goal is to capture shifts in behavior 
across regimes, I test the models using data from two different periods in U.S. history. The first is the period from 1960 to the present, when inflation has been highly persistent. The second is the period from 1879 through 1914, when the U.S. had a gold standard. In that period, the univariate process for inflation was close to white noise. As a result, my assumption of univariate forecasts implies that expected inflation was close to a constant. Like previous researchers, I find that sticky-price models fail badly at fitting the data under the assumption of rational expectations. For the post-1960 period, the assumption of backward-looking expectations fits the data well, again as others have found, but this result does not carry over to the period before 1914. Models with backward-looking expectations imply persistent effects of inflationary shocks that do not exist in the pre-1914 data. In contrast to these failures, my new assumption of optimal univariate expectations performs well for both historical periods. With these expectations, sticky-price models fit both the inflation persistence in the later period and the lack of persistence in the earlier period.

The rest of this paper contains seven sections. Section II discusses current models of expectations and Section III proposes my new approach. Section IV discusses the two historical periods that I study, Section $V$ describes my sticky-price models, and Sections VI-VII present the main empirical results. Section VIII concludes. 
II. INFLATION INERTIA AND CURRENT MODELS OF EXPECTATIONS

A. The Taylor-Calvo Model with Rational Expectations

Since the 1970s, most researchers studying inflation dynamics have used models with rational expectations. To capture the interactions of inflation and output, they often assume frictions in wage- and price-setting. In recent years, many researchers have converged on a particular specification: the Taylor-Calvo model of staggered price adjustment and the "New Keynesian Phillips curve" that it implies (Roberts, 1995). Goodfriend and King (1997) argue that the Taylor-Calvo model with rational expectations is part of a "new synthesis" in macroeconomics, and the model has become a standard tool for analyzing alternative monetary policies (e.g. Rotemberg and Woodford, 1997; McCallum and Nelson, 1999).

Unfortunately, recent research shows that the Taylor-Calvo model fails to capture a central feature of the modern economy: inflation inertia. For the postwar United States, there is strong evidence that shocks to inflation have persistent effects, and reducing inflation requires substantial output losses (e.g. Christiano et al., 1994; Romer and Romer, 1989; Ball, 1994). Recent authors use a variety of techniques to show that the Taylor-Calvo model cannot fit these facts if one assumes rational expectations. For example, Gali and Gertler (1999) show that the model produces a perverse Phillips curve: higher output leads to a fall in inflation. Similarly, Mankiw (2000) shows that the model produces implausible responses to monetary shocks, with output and inflation 
moving in opposite directions. These counterfactual predictions make the model an unreliable tool for policy analysis.

Of course, what the data reject is the combination of rational expectations with the particular specifications of price setting chosen by Taylor and Calvo. In principle, the Taylor-Calvo model might be modified to make it fit the data under rational expectations. Researchers such as Fuhrer and Moore (1995), Rotemberg and Woodford (1997), and Gali and Gertler explore variations on the model. However, no consensus has emerged on whether these variations are successful in fitting the facts. Thus other researchers, and this paper, take a different approach: relaxing the assumption of rational expectations.

\section{B. Backward-Looking Expectations}

Until the 1970s, the standard model of expectations was backward-looking: expected inflation was assumed to equal lagged inflation (or an average of several lags). Given the empirical failures of rational-expectations models, some researchers have suggested a return to backward-looking models, or models with both backward-looking and rational agents (e.g. Ball, 1991; Roberts, 1997). Backward-looking behavior helps explain inflation inertia: since firms choose prices based on expected inflation, backwardlooking expectations make inflation depend on lagged inflation. Roberts (1998) shows that the Taylor-Calvo model fits the data much better when he assumes that some price setters are backward-looking than when he assumes rational expectations for all. 
But can one justify the assumption of backward-looking expectations theoretically? If we examine only the postwar United States, the answer is yes. In recent decades, the persistence of inflation has been strong enough that current inflation is a fairly good predictor of future inflation. Inflation usually changes slowly, and the occasional large changes are often the result of unforecastable shocks, such as OPEC price rises. Consequently, backward-looking inflation forecasts are not much worse than forecasts that use information optimally.

This reasoning suggests that we can interpret backward-looking expectations as a "near-rational rule of thumb" (Akerlof and Yellen, 1985a). It is costly to gather and process the information needed for fully rational inflation forecasts. Some large firms pay these costs -- they hire economists to build forecasting models and monitor the Fed. For the local pizza parlor, however, the costs of these activities are larger than the gains from improved inflation forecasts. So the pizza parlor uses the inexpensive and reasonably accurate rule of setting expected inflation equal to past inflation. This justification for near-rational inflation forecasting parallels justifications for near-rational behavior in price adjustment (Akerlof and Yellen, 1985b) and in consumption (Cochrane, 1989).

The empirical results below support the view that backwardlooking expectations are near-rational in the current regime. If one forecasts inflation to equal past inflation, the forecast error 
is simply the change in inflation. For annual data on the GDP deflator from 1960-99, the standard deviation of inflation changes is 1.16 percentage points. If one forecasts inflation over 1960-99 with a vector autoregression including output, inflation, and a short-term interest rate, the standard error of the forecasts is 0.84 percentage points. Thus a substantial increase in the sophistication of forecasts reduces the typical error by only a few tenths of a percentage point. This improvement gives firms little incentive to abandon backward-looking expectations.

\section{The Lucas Critique}

A limitation of the preceding argument is that it relies on a feature of the economy -- the persistence of inflation -- that arises in a particular monetary regime. In other possible regimes, inflation would not be persistent, and so backward-looking expectations would be far from rational. For example, if the Federal Reserve adopted a strict price-level target, inflation would have negative serial correlation, because policy would reverse deviations from the target. In such a regime, the expectation that inflation will equal past inflation would be obviously unreasonable, and would produce large forecast errors. Firms with backward-looking expectations would have strong incentives to change their behavior.

This idea is more than a theoretical possibility. The inflation persistence in the postwar United States does not extend to earlier historical periods. In particular, the serial 
correlation of inflation in the decades before 1914 is close to zero (Barsky, 1987). As documented below, this fact implies that backward-looking expectations produce large forecast errors for that period. The pre-1914 behavior of expectations is likely to differ from its recent behavior, leading to different inflation dynamics. This idea is supported by evidence that pre-1914 Phillips curves have smaller coefficients on lagged inflation than postwar Phillips curves (Gordon, 1980; Alogoskoufis and Smith, 1991).

Because of the Lucas Critique, it is dangerous to assume backward-looking expectations when comparing different monetary regimes. The usual response to this problem is to assume rational expectations -- but in models of inflation dynamics, this assumption produces unrealistic predictions about the current regime. We need a new model of expectations that fits the current period and also makes plausible predictions about other regimes.

\section{OPTIMAL UNIVARIATE EXPECTATIONS}

What is the right near-rational model of expectations? There is inevitably some arbitrariness in answering this question. Part of the appeal of rational expectations is that it has an unambiguous definition. When one relaxes this assumption, rationality can fail in many ways -- agents can ignore various pieces of information, or make various systematic errors. (To paraphrase Tolstoy, all rational models are rational in the same 
way, but every non-rational model is non-rational in a different way.) One can imagine a deep theory of information gathering and processing that predicts deviations from rationality, but research in this area is in its infancy (e.g. Sargent, 1993). The best one can do at present is to propose plausible but ad hoc types of behavior and see whether they fit the data.'

This paper examines one type of near-rational behavior. I assume that agents predicting inflation make optimal univariate forecasts. The deviation from rationality is the fact that forecasts are univariate: agents ignore relevant variables such as output and interest rates. Aside from this limitation, agents' forecasts are optimal: they use inflation data as best they can. Metaphorically, one can imagine firms who use Box-Jenkins techniques to select an ARIMA model for inflation, but who do not go to the added trouble of using multivariate techniques.

The justification for this behavior is the same as the earlier justification for backward-looking expectations: univariate forecasting is a near-rational rule of thumb. It economizes on information costs because it requires examining only a single, obvious variable, and it produces forecast errors only modestly larger than fully rational expectations. Here, however, the justification is not specific to a particular monetary regime. In

\footnotetext{
${ }^{1}$ As Sargent puts it, "when we withdraw the assumption of a commonly understood environment, we have to replace it with something, and there are so many plausible possibilities. Ironically, when we economists make the people in our models more "bounded" in their rationality... we must be smarter...." (p. 2).
} 
my model, expectations adjust to changes in the univariate inflation process, allowing them to remain near-rational. In particular, I show below that univariate expectations are close to rational in both the post-1960 and pre-1914 periods.

My model of expectations has many antecedents. In the early days of rational expectations, Sargent (1973) and McCallum (1976) discussed the idea that expectations might be based on univariate forecasts, calling this model "partly rational expectations." McCallum suggests that lagged inflation rates are the variables "most likely to be considered by market participants" in forecasting inflation. More recently, applied researchers such as Staiger et al. (1997) use univariate forecasts as proxies for expected inflation when estimating Phillips curves.

At a broader level, I follow a number of authors who seek to explain inflation behavior with deviations from rationality. For example, "bounded rationality" is central to sargent's recent interpretation of U.S. inflation history (although sargent emphasizes bounded rationality on the part of policymakers rather than private agents). Lucas's (1973) model of the Phillips curve is another inspiration for my work, although Lucas calls the friction in his model "imperfect information" rather than nearrationality. In both Lucas's model and mine, agents ignore certain observable variables -- in his case, they ignore the price level in estimating relative prices -- but they use the information they do 
collect optimally. Thus my model builds on a theme that is common to such diverse researchers as Lucas, Sargent, and Akerlof-Yellen. Since my model is just one kind of near-rational expectations, future research should explore others. One can imagine expectations that are closer to full rationality; for example, agents might use data on output as well as inflation to forecast future inflation, while still ignoring interest rates. Or expectations could be farther from rationality; agents might use AR-1 models of inflation rather than optimal ARIMA models. A generalization of my model might include a mixture of fullyrational and less-than-rational agents, following Roberts (1997) and others. Future work can ask which variation on nearrationality best captures the behavior of inflation.

IV. EXPECTATIONS IN TWO MONETARY REGIMES

In Sections VI and VII below, I test macroeconomic models with univariate expectations in two historical periods. As preliminary steps, this section describes the two periods and presents evidence on what kinds of expectations are near-rational in each of them.

A. The Two Periods

The first period I examine is the current regime of highly persistent inflation, which I date from 1960 through the present (my data end in 1999). Some authors consider the entire period since World War II, but Barsky (1987) finds that strong inflation persistence emerged only around 1960. For the post-1960 period, 
Barsky and others find that the process for inflation has a unit root. A common interpretation is that policy has accomodated shocks to inflation, leading the shocks to have permanent effects. For annual data on the GDP deflator, an augmented DickeyFuller test confirms the finding of a unit root in inflation over 1960-1999. Therefore, I construct inflation forecasts with a stationary model for the change in inflation $(\Delta \pi)$. For annual data, I assume that the univariate behavior of $\Delta \pi$ can be approximated by an AR-2 process. Table I reports OLS estimates of the AR coefficients. Both coefficients are statistically significant but modest in size. The small coefficients confirm that inflation is fairly close to a pure random walk. ${ }^{2}$

The other period I examine is the gold-standard era from 1879 through 1914. Friedman and Schwartz (1963) argue that there were important regime shifts in 1879, when the U.S. returned to the gold standard, and in 1914, when the Federal Reserve was established. As discussed above, previous work finds that inflation was close to white noise during this period -- the price level was close to a random walk. Shocks such as gold discoveries and shifts in money demand produced one-time changes in the price level.

I reexamine the inflation process for 1879-1914 using the two leading series for the output deflator, those of Balke and Gordon (1989) and Romer (1989). For each series, Table I reports

\footnotetext{
${ }^{2}$ I do not include a constant in the model for $\Delta \pi$. This means I assume no deterministic drift in the level of inflation.
} 
estimates of AR-2 models for the level of inflation. All the coefficients are small and statistically insignificant, confirming that inflation was close to white noise. The constant in the equation is also close to zero, implying that the univariate forecast of inflation is close to zero in all years.

In the empirical work below, I assume that the periods 1960-99 and 1879-1914 are stable monetary regimes, and that price setters know the univariate inflation process in each period. The assumption of stable regimes appears reasonable. Some authors suggest that there were regime shifts in 1979 (the Volcker appointment and change in operating procedures) or 1986 (when Taylor's (1993) interest-rate rule begins to fit the data). However, Chow tests based on these dates fail to reject a stable inflation process over 1960-1999 ( $p=0.20$ for 1979 and $p=0.77$ for 1986).

Even if the inflation process is stable, it is questionable to assume that agents know the process throughout the regime. This assumption is weaker than the usual rational-expectations hypothesis, in which agents know the entire structure of the economy. However, as stressed by Sargent (1999), agents are not endowed with a priori knowledge of inflation behavior. Instead, they must learn about it over time, perhaps by reestimating the inflation process as new data arrive. Future work should combine this idea about learning with my idea of limited information sets. One could assume, for example, that expectations are determined by 
real-time estimates of the univariate inflation process rather than the true process.

B. What Expectations Are Near-Rational?

I argue above that optimal univariate forecasts are a nearrational form of expectations in many monetary regimes. In contrast, backward-looking expectations are near-rational only if inflation is highly persistent. Here I confirm these ideas by computing forecast errors for various kinds of expectations.

As a benchmark, I first compute errors based on optimal multivariate forecasts. For both the pre-1914 and post-1960 periods, I forecast annual inflation based on lags of inflation, output, and a short-term interest rate. Output is defined as detrended real GNP (for the early period) or GDP (for the later period); the trend is measured by the Hodrick-Prescott filter with smoothing parameter 1000. Inflation is the percentage change in the GNP or GDP deflator. For the early period, output and inflation data are taken from both Romer and Balke-Gordon. The interest rate for the later period is the Treasury bill rate; for the early period it is the commercial paper rate from the NBER Macro History Database.

As discussed above, inflation appears to be non-stationary for the post-1960 period. Following Roberts (1998), I assume that the nominal interest rate is also non-stationary, and that the real interest rate, $r=i-\pi$, is stationary. (Equivalently, $i$ and $\pi$ are cointegrated). For the post-1960 period, I forecast inflation by 
regressing the change in inflation on lags of the stationary variables $y, \Delta \pi$, and $r$. For the pre-1914 period, I regress inflation on $y, \pi$, and $i$. For each period, I include two lags of all variables.

Table II presents the standard errors of these multivariate forecasting equations. For the post-1960 period, the standard error is 0.84. For the pre-1914 period, the standard error is 2.10 for the Balke-Gordon data and 3.26 for the Romer data, reflecting greater inflation variability in the earlier period.

Table II also reproduces the standard errors of optimal univariate forecasts from Table I. These exceed the errors from multivariate forecasts by only a few tenths of a percentage point: the increase is 0.25 percentage points in the post-1960 period, and 0.30 and 0.15 for the two pre-1914 data sets. Note that output and interest rates usually do make some contribution to forecasting inflation: in the multivariate equations, these variables are jointly significant for the post-1960 data $(p<0.01)$ and for the Balke-Gordon version of the pre-1914 data $(p=0.02)$. But the size of the forecast improvements from adding these variables is modest, making it plausible that near-rational agents would ignore them.

Finally, Table II presents standard errors for backwardlooking expectations, $\pi_{\mathrm{t}}{ }^{\mathrm{e}}=\pi_{\mathrm{t}-1}$. As discussed in Section II, these are not much larger than multivariate forecast errors for the post-1960 period. But in the pre-1914 period, errors for backward-looking expectations exceed errors for multivariate forecasts by 1.02 
percentage points in the Balke-Gordon data and 1.36 points in the Romer data. These increases in standard errors are much larger than the increases from using univariate forecasts. These findings confirm that backward-looking expectations are far from rational in the pre-1914 period.

V. MODELS OF PRICE SETTING

This section describes two models of price adjustment, which I go on to test under alternative assumptions about expectations. Both models are based on the canonical macroeconomic model of imperfect competition (Romer, 1996, ch. 6), but they differ in the timing of price changes. The first model follows Taylor (1979): I assume that each firm sets its price for two periods, and that adjustment is staggered across firms. In the second model, each firm adjusts its price every period. In this case, nominal rigidity arises because some firms set prices before observing the current state.

The model with staggered adjustment has the advantage that much recent research uses similar models; thus my tests of this model are directly comparable to previous work. For my purposes, however, the model with staggering also has a major drawback: estimating it requires data at greater than an annual frequency • The reason, as detailed below, is that a plausible calibration sets a period in the model equal to half a year. Unfortunately, only annual data on output are available for the pre-1914 period. I 
therefore use my second price-adjustment model, which requires only annual data, to compare the pre-1914 and post-1960 periods.

A. The Model with Staggered Adjustment

The economy contains a large number of imperfectly competitive firms. Each firm's desired price in period t is given by

$$
p_{t}^{*}=p_{t}+v y_{t}, \quad v>0,
$$

where $p^{*}$ is the desired nominal price, $p$ is the aggregate price level, and $y$ is aggregate output (all variables are in logs). Equation (1) can be derived from profit-maximization when firms have isoelastic cost and demand functions (Romer, ch. 6). Intuitively, a rise in output shifts out each firm's demand curve, raising its desired relative price.

In this version of the model, a firm sets a fixed price for two periods. Let $x_{t}$ denote the price set by firms in period $t$ for $t$ and $t+1$. This price is chosen after firms observe the state of the economy at t. Following Taylor (1979) and Roberts (1995), firms set $x_{t}$ equal to the average of expected optimal prices at $t$ and $t+1$ :

$$
x_{t}=\frac{1}{2}\left(p_{t}^{*}+E_{t} p_{t+1}^{*}\right)
$$

where $E_{t}$ denotes firms' expectations at time $t$. Note that $E_{t}$ may or may not equal a mathematical expectation, depending on whether we assume rational expectations.

Price setting is staggered, with equal numbers of firms adjusting each period. Thus the price level $p_{t}$ is the average of $x_{t}$ and $\mathrm{x}_{\mathrm{t}-1}$ :

$$
p_{t}=\frac{1}{2}\left(x_{t}+x_{t-1}\right)
$$


As shown by Roberts (1995), equations (1)-(3) and algebra yield an equation for inflation, $\pi_{t} \equiv p_{t}-p_{t-1}$ :

$$
\pi_{t}=\frac{1}{2}\left(E_{t} \pi_{t+1}+E_{t-1} \pi_{t}\right)+\frac{v}{2}\left(y_{t}+E_{t} y_{t+1}+y_{t-1}+E_{t-1} y_{t}\right)+\varepsilon_{t},
$$

where $I$ add an error $\varepsilon_{t}$ to capture inflation shocks not explained by the model. I assume that $\varepsilon_{\mathrm{t}}$ is serially uncorrelated and uncorrelated with $\mathrm{y}_{\mathrm{t}}$.

Equation (4) is one version of the popular "New Keynesian Phillips curve." According to the equation, inflation depends on expected inflation in the current and future periods, and on output terms. The empirical work below examines the performance of this equation. ${ }^{3}$

\section{B. The Model with Prices set for One Period}

In the second model of price adjustment, firms' desired prices are again given by equation (1). Each firm sets its price one period at a time. A fraction w of firms, the "sticky-price"

${ }^{3}$ Equation (4) is similar to equation (8) in Roberts (1995). Roberts, however, writes the equation differently. He replaces the term $E_{t-1} \pi_{t}$ with $\pi_{t}+u_{t}$, where $u_{t}$ is an expectational error $\left(u_{t} \equiv E_{t-1} \pi_{t}\right.$ $\left.-\pi_{t}\right)$. Making this substitution and rearranging leads to

$$
\text { (4') } \quad \pi_{t}=E_{t} \pi_{t+1}+v\left(y_{t}+E_{t} y_{t+1}+y_{t-1}+E_{t-1} y_{t}\right)+2 \varepsilon_{t}+u_{t} \text {. }
$$

Here, the only inflation expectation that appears explicitly is $E_{t} \pi_{t+1}$ - the Phillips curve appears to be fully "forward-looking." But $E_{t-1} \pi_{t}$ enters the equation through the error $u_{t}$. (This result depends on Taylor's assumption of fixed intervals between price adjustments. As shown by Roberts, Calvo's assumption of random adjustments produces a version of (4') without the $u_{t}$ term.) 
sector, must set prices one period in advance. They set their prices equal to the expected optimal price:

$$
p_{t}^{s}=E_{t-1} p_{t}^{*}
$$

The other firms, the "flexible-price" sector, set prices after observing the current state. Their prices are

$$
p_{t}^{f}=p_{t}^{*} \text {. }
$$

I include the flexible-price sector to allow output to have some effect on inflation within a period.

The aggregate price level is a weighted average of $\mathrm{p}^{\mathrm{s}}$ and $\mathrm{p}^{\mathrm{f}}$ :

$$
p_{t}=w p_{t}^{s}+(1-w) p_{t}^{f} .
$$

This equation and (1), (5), and (6) lead to

$$
p_{t}=E_{t-1} p_{t}+v E_{t-1} y_{t}+\frac{(1-w) v}{w} y_{t} \text {. }
$$

Subtracting $p_{t-1}$ from each side yields another phillips curve:

$$
\pi_{t}=E_{t-1} \pi_{t}+v E_{t-1} y_{t}+\frac{(1-w) v}{w} y_{t}+\varepsilon_{t},
$$

where $I$ again add an error $\varepsilon_{t}$. This equation is similar in spirit to the earlier Phillips curve: inflation depends on expected inflation and output terms. However, the dynamic structure is simpler than before.

VI. TESTING THE MODEL WITH STAGGERING

The rest of this paper examines the empirical performance of my sticky-price models under rational expectations, backwardlooking expectations, and optimal univariate expectations. In this section, I embed these expectational assumptions in the model with staggered price adjustment. 
In calibrating the model, a key parameter is the frequency of price adjustment. Following Fuhrer-Moore and Roberts, I assume that each firm adjusts once per year. This assumption is consistent with the finding that the median U.S. firm adjusts at this frequency (Blinder et al., 1998). Since a firm in the staggering model adjusts every two periods, annual adjustment means a period is interpreted as half a year. I therefore estimate the model with semi-annual data, which are available only for the post1960 period. ${ }^{4}$

A. The Model with Rational Expectations

A number of previous authors test my model of staggered price adjustment (or similar models) under the assumption of rational expectations. These tests usually produce strong rejections (e.g. Estrella and Fuhrer, 1998; Mankiw, 2000). Gali and Gertler (1999) present an especially simple demonstration of the model's failure. They estimate the model's Phillips curve, equation (4), and obtain a negative coefficient on the output term; this result contradicts the underlying theory. Here I assume rational expectations and replicate Gali and Gertler's negative result. This exercise provides a benchmark when I examine the model's performance with other kinds of expectations.

\footnotetext{
${ }^{4}$ In this section, the inflation and interest rate variables are the semi-annual analogues of the variables defined in section IV. To obtain the output gap, I detrend quarterly output with the HP filter $(\lambda=16,000)$ and then aggregate the quarterly gap series.
} 
To estimate equation (4), I first replace all expected variables with actual variables plus expectational errors. This yields

$$
\pi_{t}=\frac{1}{2}\left(\pi_{t+1}+\pi_{t}\right)+\frac{v}{2}\left(y_{t-1}+2 y_{t}+y_{t+1}\right)+\varepsilon_{t}+u_{t}+u_{t+1},
$$

where $u_{t}$ is an expectational error $\left(u_{t} \equiv(1 / 2)\left(E_{t-1} \pi_{t}-\pi_{t}\right)+(v / 2)\left(E_{t-1} y_{t}-\right.\right.$ $\left.y_{t}\right)$. Note there are two expectational errors, $u_{t}$ and $u_{t+1}$, because equation (4) includes expectations of variables at $t$ and $t+1$. Equation (10) simplifies to

$$
\pi_{t}-\pi_{t+1}=v\left(y_{t-1}+2 y_{t}+y_{t+1}\right)+2\left(\varepsilon_{t}+u_{t}+u_{t+1}\right) .
$$

The parameter $\mathrm{V}$ in (11) can be estimated by instrumental variables. As instruments, I use the output gap, the change in inflation, and the real interest rate from t-1 through t-4. Under rational expectations, these lagged variables are uncorrelated with the expectational errors $u_{t}$ and $u_{t+1}$. They are also uncorrelated with the white-noise error $\varepsilon_{t}$ in the underlying inflation equation.

The instrumental variables estimate of $v$ is -0.049 , with a Newey-West standard error of 0.016 . Thus the estimate is significantly negative. Recall that $v$ is the effect of output on firms' desired prices in equation (1). The model of monopolistic competition underlying (1) implies that $v$ is positive. Thus, like Gali and Gertler, I find that the estimate of $v$ contradicts theory. There is a straightforward explanation for the model's failure. For v>0, equation (11) gives a positive relation between $\pi_{t}-\pi_{t+1}$ and an average of output from $t-1$ to $t+1 . \pi_{t}-\pi_{t+1}$ equals $-\Delta \pi_{t+1}$, so this means a negative relation between output and the change in 
inflation. In the data, however, there is a positive relation between output and $\Delta \pi_{t+1}--$ the accelerationist Phillips curve. This contradiction between the model's Phillips curve and the one in the data produces the model's rejection.

B. The Model with Optimal Univariate Expectations

I now show that the model of staggered price adjustment performs better if rational expectations are replaced by optimal univariate expectations. As a first step, I reestimate the model's Phillips curve, equation (4), and show that the parameter $\mathrm{v}$ has the correct sign.

In this version of the model, I replace the expected inflation terms in equation (4) with optimal univariate forecasts. For consistency, I assume that output expectations are also given by univariate forecasts. Semi-annual inflation forecasts are generated by an AR-4 model for $\Delta \pi$ with coefficients $\rho_{1}, \ldots, \rho_{4}$; output forecasts are generated by an AR-4 with coefficients $\beta_{1}, \ldots, \beta_{4}$. These assumptions determine the expectations in (4) in terms of the AR parameters and current and lagged variables. For example, $E_{t} \pi_{t+1}$ equals $\pi_{t}+\rho_{1}(\Delta \pi)_{t}+\ldots+\rho_{4}(\Delta \pi)_{t-3}$. Substituting expressions like this into (4) leads, after algebra, to

$$
\begin{aligned}
& \pi_{t}-\frac{1}{1-\rho_{1}}\left\{\begin{array}{c}
\left(1+\rho_{2}\right) \pi_{t-1}+\left(-\rho_{1}+\rho_{3}\right) \pi_{t-2}+ \\
\left(-\rho_{2}+\rho_{4}\right) \pi_{t-3}-\rho_{3} \pi_{t-4}-\rho_{4} \pi_{t-5}
\end{array}\right\}= \\
& \frac{v}{1-\rho_{1}}\left\{\begin{array}{l}
\left(1+\beta_{1}\right) y_{t}+\left(1+\beta_{1}+\beta_{2}\right) y_{t-1}+ \\
\left(\beta_{2}+\beta_{3}\right) y_{t-2}+\left(\beta_{3}+\beta_{4}\right) y_{t-3}+\beta_{4} y_{t-4}
\end{array}\right\}+2 \varepsilon_{t} .
\end{aligned}
$$


To estimate this equation, I first estimate the AR processes for $\Delta \pi$ and $y$ and substitute the estimates of $\rho^{\prime} s$ and $\beta^{\prime} s$ into equation (12). With the AR coefficients replaced by numbers, (12) has a single parameter, v. I can estimate v by ordinary least squares, since the error $\varepsilon$ is uncorrelated with output and its own lags. The estimate of $\mathrm{v}$ is 0.058 with a standard error of $0.014 .^{5}$ Thus, in contrast to the case of rational expectations, the estimated $v$ has the positive sign predicted by theory. To understand why, recall that inflation is close to a random walk in the post-1960 period; thus, with univariate forecasts, $E_{t-1} \pi_{t}$ is close to $\pi_{t-1}$. Roberts and others have shown that replacing $E_{t-1} \pi_{t}$ with $\pi_{t-1}$ helps staggered-price-setting models fit the data. Specifically, if this substitution is made in equation (4), the equation reduces to a positive relation between $\Delta \pi$ and output - the Phillips curve that appears in the data.

5 The estimated parameters substituted into equation (12) are $\rho_{1}=0.029, \rho_{2}=0.049, \rho_{3}=-0.084, \rho_{4}=-0.099, \beta_{1}=1.237, \beta_{2}=-0.476, \quad \beta_{3}=-$ 0.114 , and $\beta_{4}=0.068$. In principle, my use of generated coefficients makes the OLS standard error for $v$ invalid (Pagan, 1984). My problem is sufficiently non-standard that it is difficult to generate the correct standard error. However, Monte Carlo evidence suggests that the OLS standard error is close to correct in this application. I generate artificial data that mimic the outputinflation dynamics in the true data using a VAR for $y$ and $\Delta \pi$ and bootstrap techniques. I create 50,000 artificial data sets, each the same size as the true data set (80 observations). For each artificial sample, I estimate $v$ using my two-step procedure. The standard deviation of the estimated $V^{\prime} s$ across samples is 0.015 . This bootstrap standard error is close to the OLS standard error of 0.014 . 
Obtaining a coefficient estimate with the correct sign is fairly weak confirmation of a model. I can, however, construct a stronger test of the model's quantitative implications. To do so, I first summarize the inflation-output interactions in the data by estimating an unrestricted, atheoretical Phillips curve. Specifically, I regress the change in inflation on four lags of itself, current output, and four lags of output; then I transform the results to obtain an equation for the level of inflation. The first column of Table II reports coefficient estimates and standard errors for this equation. (Once again, I estimate an equation for $\Delta \pi$ because inflation is non-stationary.)

In equation (12), moving the lagged-inflation terms to the right side yields a restricted version of the atheoretical Phillips curve. Once the estimated $\rho^{\prime} s$ and $\beta^{\prime} s$ are substituted in, the coefficients on all the output and inflation lags are determined by one parameter, $v$. The second column of Table III gives the coefficients that arise when $\mathrm{V}$ is set at its OLS estimate of 0.058 . To test the model, I test the hypothesis that all the coefficients in the unrestricted Phillips curve equal their values in the restricted Phillips curve. ${ }^{6}$

An F-test fails to reject the equality of restricted and unrestricted coefficients $(p=0.66)$. Most important, Table III

\footnotetext{
${ }^{6}$ This test treats the coefficients in the restricted equation as constants; it ignores sampling error in estimating these coefficients. This appears to bias the test toward rejection of the model's restrictions. Nonetheless, the restrictions are not rejected.
} 
shows that the two sets of coefficients are close in economic terms. In both cases, the first inflation lag has a coefficient near one and the longer lags have coefficients near zero. And in both cases, there are positive coefficients on current output and one or two output lags. The sum of output coefficients is 0.25 in the unrestricted equation and 0.21 in the restricted equation. Thus the Phillips curve derived from the model is consistent with the stylized facts.

\section{The Model with Backward-Looking Expectations}

The final version of the staggered-adjustment model assumes backward-looking expectations: $\mathrm{E}_{\mathrm{t}-1} \pi_{\mathrm{t}}=\pi_{\mathrm{t}-1}$. The results for this case are similar to the results for optimal univariate expectations. This reflects the fact that the two models of expectations are nearly equivalent for the post-1960 period.

In equation (4), I substitute $\pi_{t-1}$ for $E_{t-1} \pi_{t}$ and $\pi_{t}$ for $E_{t} \pi_{t+1}$. I assume that output expectations are also backward-looking and substitute lagged output for expected output. Equation (4) reduces to

$$
\pi_{t}-\pi_{t-1}=v\left(2 y_{t-1}+2 y_{t}\right)+2 \varepsilon_{t} .
$$

The OLS estimate of the parameter $\mathrm{v}$ is 0.056 with a standard error of 0.013 .

Equation (13) is another restricted version of the atheoretical Phillips curve. In Table III, the third column gives the Phillips-curve coefficients implied by (13) with $v=0.056$. Once again, one cannot reject the hypothesis that the unrestricted 
coefficients equal the restricted coefficients. And once again, the restricted and unrestricted equations tell the same economic story. Inflation depends on lagged inflation with a coefficient near one (or exactly one in column (3)), and on output terms.

I would like to test the model with backward-looking expectations against the model with optimal univariate forecasts. However, this is not practically possible with post-1960 data, because the models' implications are so similar for this period. I therefore turn to data for the period before 1914, when the two kinds of expectations differ greatly.

VII. TESTING THE MODEL WITH ONE-PERIOD PRICES

This section tests the second version of my sticky-price model, in which a firm adjusts its price every period. I again assume that prices are adjusted once per year, which means here that a period is a year. I can therefore test the model for the pre-1914 period, when only annual data are available, as well as the post-1960 period.

A. Rational Expectations

It is easy to see that the model with one-period prices is rejected if one assume rational expectations. Paralleling the analysis in the previous section, I start with the model's Phillips curve, equation (9), and replace expected variables with actual variables plus expectational errors. This yields

$$
\pi_{t}=\pi_{t}+\frac{v}{w} y_{t}+\varepsilon_{t}+u_{t}
$$


where $u_{t} \equiv E_{t-1} \pi_{t}-\pi_{t}+v\left(E_{t-1} y_{t}-y_{t}\right)$. The $\pi_{t}^{\prime}$ s cancel out, leaving

$$
0=\frac{v}{w} y_{t}+\varepsilon_{t}+u_{t}
$$

One can again estimate the output coefficient, v/w, by instrumental variables. Since the left side of (15) is zero, the estimate is obviously zero. This implies $\mathrm{v}=0$, which contradicts the model's assumption of $\mathrm{v}>0$.

To see the problem more intuitively, consider the model's implications when $v>0$. In this case, equation (9) gives a positive relation between $\pi_{t}-E_{t-1} \pi_{t}$ and actual and expected output. Thus variables that help forecast output also help forecast $\pi_{t}-E_{t-1} \pi_{t}$. This result contradicts rational expectations, which implies that $\pi_{t}-E_{t-1} \pi_{t}$ is unforecastable.

These results depend, of course, on the model's simple timing of price adjustment. As shown earlier, the staggered-adjustment model with rational expectations produces an estimate of $\mathrm{v}$ which is negative rather than zero. However, both a zero $v$ and a negative $v$ violate theory. The failure of rational expectations is a robust result, although the failure takes different forms in the two price-setting models.

\section{B. Optimal Univariate Expectations}

Like the earlier model with staggering, the model with oneperiod prices fits the data fairly well if one assumes optimal univariate expectations. I show this is true for annual data from both 1960-1999 and 1879-1914. 
The Model's Phillips Curve: With annual data, I use the forecasting models for inflation in Table I: an AR-2 for $\Delta \pi$ in the post-1960 period and an AR-2 for the level of $\pi$ in the pre-1914 period. In both periods I use an AR-2 for output to measure output expectations. For each period, I substitute the forecasting models into equation (9) and obtain inflation in terms of lagged inflation and current and lagged output. I omit these equations, which are the analogues of equation (12) for the model with staggering. Once estimates of the AR coefficients are substituted in, there are two free parameters, the coefficients on $E_{t-1} Y_{t}$ and $y_{t}$ in (9). In terms of underlying parameters, these coefficients equal $v$ and $(1-w) v / w$.

Table IVA presents OLS estimates of the two output coefficients for the 1960-1999 and 1879-1914 periods. For the post1960 period, the two coefficients are positive, and they are jointly significant at the one percent level. The estimates for 1879-1914 are imprecise, especially for the Romer data, reflecting the high inflation variability in the period. For both pre-1914 data sets, the $y_{t}$ coefficient is positive but the $E_{t-1} y_{t}$ coefficient is negative, contradicting theory. However, the negative coefficients are far from significant, and confidence intervals include large positive values. Thus the pre-1914 data neither reject nor strongly support the model's predictions about output effects.

Again paralleling earlier analysis, I test the restrictions that the model places on an atheoretical Phillips curve. Table IVB 
presents unrestricted Phillips curves and the Phillips curves implied by equation (9) with univariate expectations. The coefficients in (9) are set at the estimated values in Table IVA. For the post-1960 period, the unrestricted equation is once again obtained by estimating an equation for $\Delta \pi$; for the pre-1914 period, I estimate an equation for $\pi$ directly.

One cannot reject the hypothesis that the unrestricted coefficients equal the restricted coefficients for either 1960-1999 or 1879-1914 (the p-values are 0.3 and higher). In comparing the restricted and unrestricted equations, the output coefficients are not very informative, because they are estimated imprecisely. The coefficients on inflation lags are more interesting. For the post1960 data, the sum of these coefficients is close to one in both the restricted and unrestricted equations (as found before with semi-annual data). For the pre-1914 data, the sum of coefficients is less than 0.3 in both equations. Thus the restricted and unrestricted Phillips curves shift across time in the same way.

Previous papers such as Gordon (1980) and Algoskoufis-Smith (1991) have pointed out the shift across regimes in laggedinflation coefficients in unrestricted Phillips curves. As shown below, the success in capturing this shift is what distinguishes my model of univariate expectations from backward-looking expectations. The reasons for the model's behavior should be clear. In the model, lagged inflation rates enter the Phillips curve to the extent they influence univariate inflation forecasts. 
In going from the post-1960 to the pre-1914 period, the inflation process becomes less persistent, so lagged inflation has smaller effects on forecasts.

Impulse Response Functions: To illustrate the performance of the model, I borrow a technique from Fuhrer-Moore (1995) and Roberts (1998): comparison of restricted and unrestricted impulse response functions. I first combine the unrestricted Phillips curve estimated above with an equation for output in terms of lagged output and lagged inflation. These two equations are a vector autoregression in recursive form (contemporaneous output affects inflation but not vice-versa). For each time period, I derive impulse response functions from the VAR; these summarize the output-inflation interactions to be explained.

I then replace the inflation equation in the VAR with the Phillips curve from my model -- equation (9) with expectations given by univariate forecasts. I leave the output equation unchanged. The resulting system yields impulse responses that embody the model's restrictions on inflation behavior.

This exercise requires values for the coefficients on $\mathrm{y}_{\mathrm{t}}$ and $\mathrm{E}_{\mathrm{t}}$ ${ }_{1} \mathrm{Y}_{\mathrm{t}}$ in equation (9). For the post-1960 period, I use the point estimates in Table IVA. For the pre-1914 period, recall that the $\mathrm{E}_{\mathrm{t}-1} \mathrm{Y}_{\mathrm{t}}$ coefficient is negative, violating theory, but highly insignificant. For this period, I set the $E_{t-1} Y_{t}$ coefficient to zero (the lower bound of its theoretical range) and reestimate the 
coefficient on $y_{t}$. The new $y_{t}$ coefficient is 0.26 for the Romer data and 0.11 for Balke-Gordon. ${ }^{7}$

Figure 1 shows the impulse responses of inflation to output and inflation shocks for the post-1960 and two pre-1914 data sets. The solid lines in the graphs are responses derived from the unrestricted VAR, and the dashed lines are restricted responses. The graphs also show 95\% confidence bands for the unrestricted responses, derived by bootstrap methods. The central message of the Figure is that the restricted and unrestricted responses are similar. In particular, the restricted responses almost always lie within the confidence intervals for the unrestricted responses. ${ }^{8}$

Recall that pre-1914 Phillips curves have lower coefficients on lagged inflation than post-1960 Phillips curves. This difference is reflected in the persistence of inflation responses in Figure 1. In both periods, inflation initially rises after an output or inflation shock. In the post-1960 period, inflation remains high permanently (although, for inflation shocks, the long-run response is smaller than the initial response). In the early period, by contrast, the effects of shocks die out quickly. Again, these results arise for both restricted and unrestricted impulse responses.

\footnotetext{
7 I have also experimented with other coefficient values. My qualitative results are robust for wide ranges of values, as long as the coefficients on both $y_{t}$ and $E_{t-1} y_{t}$ are non-negative.

${ }^{8}$ I have also computed responses of output to output and inflation shocks. The restricted and unrestricted responses are very close, reflecting the fact that the model does not restrict the output equation in the VAR.
} 


\section{Backward-Looking Expectations}

Finally, I examine the model with one-period prices under backward-looking expectations. This specification fits the post1960 data, but it is strongly rejected for the pre-1914 period.

With backward-looking expectations, I substitute $\pi_{\mathrm{t}-1}$ for $\mathrm{E}_{\mathrm{t}-1} \pi_{\mathrm{t}}$ and $y_{t-1}$ for $E_{t-1} y_{t}$ in equation (9). I then estimate the equation's two coefficients by OLS. Table VA presents the coefficient estimates, which are similar to those for the univariateexpectations case.

Again paralleling earlier analysis, Table VB compares the Phillips curve derived from the model to an unrestricted Phillips curve. The results differ sharply across time periods. The hypothesis that the unrestricted coefficients equal the restricted coefficients is not rejected for the post-1960 period, but it is rejected at the $99 \%$ level for both of the pre-1914 data sets.

These results are explained by the coefficients on lagged inflation in the Phillips curves. Under backward-looking expectations, the first inflation lag always has a coefficient of one in the restricted equation. The unrestricted Phillips curve is consistent with this result for the post-1960 period, but, as discussed before, the pre-1914 coefficient is much less than one. The unrestricted Phillips curve shifts in a way that is not captured by the backward-looking model.

Paralleling Figure 1, Figure 2 compares unrestricted impulse responses for inflation to restricted responses, derived as before 
by replacing the VAR inflation equation with the model's Phillips curve. The Figure confirms the model's failure for the pre-1914 period: for both the Romer and the Balke-Gordon data, the restricted impulse responses travel far away from the unrestricted responses. Specifically, the unrestricted responses die out quickly but the restricted responses do not. The backward-looking model imposes inflation persistence that does not exist in the pre1914 data. $^{9}$

VIII. CONCLUSION

This paper proposes a near-rational model of expectations: agents make optimal univariate forecasts of inflation and output. This assumption helps to explain the behavior of U.S. inflation in two different periods, 1960-99 and 1879-1914. In contrast, neither fully rational expectations nor backward-looking expectations fits both periods.

My model of expectations meets Lucas's (1976) criterion for reliable policy analysis: it holds across different monetary regimes. In future work, I will apply the model to normative questions about monetary policy, such as the choice of an instrument or target rule. This analysis will account for shifts in expectations as new policies change the univariate behavior of

9 To derive the restricted impulse responses for the pre-1914 period, I again set the coefficient on $E_{t-1} Y_{t}$ to zero in equation (9) and reestimate the coefficient on $y_{t}$. The new $y_{t}$ coefficient is 0.17 for the Romer data and 0.08 for Balke-Gordon. 
output and inflation. I hope this approach yields more credible results than policy analysis based on fully rational expectations (e.g. McCallum and Nelson, 1999) or backward-looking expectations (e.g. Ball, 1999). 
REFERENCES

Akerlof, George A., and Janet L. Yellen, "Can Small Deviations from Rationality Make Significant Differences to Economic Equilibria?" American Economic Review 75 (September 1985a), $708-20$.

, "A Near-Rational Model of the Business Cycle, with Wage and Price Inertia," Quarterly Journal of Economics 100 (Supplement 1985b), 823-38.

Alogoskoufis, George S., and Ron Smith, "The Phillips Curve, the Persistence of Inflation, and the Lucas Critique: Evidence from Exchange-Rate Regimes," American Economic Review 81 (December 1991), 1254-75.

Balke, Nathan S., and Robert J. Gordon, "The Estimation of Prewar Gross National Product: Methodology and New Evidence," Journal of Political Economy 97 (February 1989), 38-92.

Ball, Laurence, "The Genesis of Inflation and the Costs of Disinflation," Journal of Money, Credit, and Banking 23 (August 1991, Part 2), 439-52. Mankiw (ed.), Monetary Policy, University of Chicago Press, 1994 .

, "Efficient Rules for Monetary Policy," International Finance 2 (April 1999), 63-83.

Barsky, Robert B., "The Fisher Hypothesis and the Forecastability and Persistence of Inflation," Journal of Monetary Economics 19 (January 1987), 3-24.

Blinder, Alan S., et al, Asking about Prices: A New Approach to Understanding Price Stickiness, New York: Russell Sage Foundation, 1998.

Calvo, Guillermo A., "Staggered Contracts in a Utility-Maximizing Framework," Journal of Monetary Economics 12 (1983), 383-98.

Christiano, Lawrence J., Martin Eichenbaum, and Charles Evans, "The Effects of Monetary Policy Shocks: Evidence from the Flow of Funds," Review of Economics and Statistics 78 (February 1996), 16-34.

Cochrane, John H., "The Sensitivity of Tests of the Intertemporal Allocation of Consumption to Near-Rational Alternatives," American Economic Review 79 (June 1989), 319-37. 
Estrella, Arturo, and Jeffrey C. Fuhrer, "Dynamic Inconsistencies: Counterfactual Implications of a Class of Rational Expectations Models," Federal Reserve Bank of Boston, Working Paper No. 98-5 (1998).

Fischer, Stanley, "Long-Term Contracts, Rational Expectations, and the Optimal Money Supply Rule," Journal of Political Economy 85 (February 1977), 191-205.

Friedman, Milton, and Anna J. Schwartz, A Monetary History of the United States, 1867-1960, Princeton University Press, 1963.

Fuhrer, Jeffrey C., "The (Un) Importance of Forward-Looking Behavior in Price Specifications," Journal of Money, Credit, and Banking 29 (August 1997), 338-50.

and George R. Moore, "Inflation Persistence, " Quarterly Journal of Economics 110 (February 1995), 127-60.

Gali, Jordi, and Mark Gertler, "Inflation Dynamics: A Structural Econometric Approach," Journal of Monetary Economics 44 (October 1999), 195-222.

Goodfriend, Marvin, and Robert King, "The New Neoclassical Synthesis and the Role of Monetary Policy," NBER Macroeconomics Annual 12 (1997), 231-83.

Gordon, Robert J., "A Consistent Characterization of a NearCentury of Price Behavior," American Economic Review 70 (May $1980), 243-49$.

Lucas, Robert E. Jr., "Some International Evidence on OutputInflation Tradeoffs," American Economic Review 63 (1973), $326-34$.

', "Econometric Policy Evaluation: A Critique, "
Carnegie-Rochester Conference Series on Public Policy 1
$(1976), 19-46$.

Mankiw, N. Gregory, "The Inexorable and Mysterious Tradeoff Between Inflation and Unemployment," Economic Journal, forthcoming.

McCallum, Bennett T., "Rational Expectations and the Natural Rate Hypothesis: Some Consistent Estimates," Econometrica 44 (January 1976), 43-52.

and Edward Nelson, "Performance of Operational Policy Rules in an Estimated Semi-Classical Structural Model," in John B. Taylor (ed.) Monetary Policy Rules, University of Chicago Press, 1999. 
Pagan, Adrian, "Econometric Issues in the Analysis of Regressions with Generated Regressors," International Economic Review 25 (February 1984), 221-47.

Roberts, John M., "New Keynesian Economics and the Phillips Curve," Journal of Money, Credit, and Banking 27 (November 1995), 975-84. , "Is Inflation Sticky?" Journal of Monetary Economics 39 (July 1997), 173-96.

, "Inflation Expectations and the Transmission of Monetary Policy," Board of Governors of the Federal Reserve, Finance and Economics Discussion Series Paper No. 1998-43 (1998) .

Romer, Christina D., "The Prewar Business Cycle Reconsidered: New Estimates of Gross National Product, 1869-1908," Journal of Political Economy 97 (February 1989), 1-37.

, and David H. Romer, "Does Monetary Policy Matter: A New Test in the Spirit of Friedman and Schwartz," NBER Macroeconomics Annual 4 (1989), 121-70.

Romer, David H., Advanced Macroeconomics, McGraw-Hill, 1996.

Rotemberg, Julio, and Michael Woodford, "An Optimization-Based Econometric Framework for the Evaluation of Monetary Policy," NBER Macroeconomics Annual 12 (1997).

Rudebusch, Glenn, and Lars E.O. Svensson, "Policy Rules for Inflation Targeting," in John B. Taylor (ed.) Monetary Policy Rules, University of Chicago Press, 1999.

Sargent, Thomas J., "Rational Expectations, the Real Rate of Interest, and the Natural Rate of Unemployment," Brookings Papers on Economic Activity 1973:2, 429-72.

, Bounded Rationality in Macroeconomics, Oxford University Press, 1993. , The Conquest of American Inflation, Princeton University Press, 1999.

Staiger, Douglas, James H. Stock, and Mark W. Watson, "How Precise Are Estimates of the Natural Rate of Unemployment?," in Christina Romer and David Romer (eds.), Reducing Inflation: Motivation and Strategy, University of Chicago Press, 1997. 
Taylor, John B., "Staggered Wage Setting in a Macro Model," American Economic Review 69 (May, 1979), 108-13.

, "Discretion Versus Policy Rules in Practice," Carnegie-Rochester Conference Series on Public Policy 39 (1993), 195-214. 
Table 1: Univariate Models of Inflation

\begin{tabular}{ccccc}
\hline 1960-1999 & & $\begin{array}{c}1879-1914 \text { (Balke-Gordon) } \\
\text { Dependent Vbl: } \pi_{\mathrm{t}}\end{array}$ & $\begin{array}{c}\text { 1879-1914 (Romer) } \\
\text { Dependent Vbl: } \pi_{\mathrm{t}}\end{array}$ \\
\hline & & constant & 0.235 & 0.497 \\
& & & $(0.400)$ & $(0.572)$ \\
$(\Delta \pi)_{\mathrm{t}-1}$ & 0.311 & $\pi_{\mathrm{t}-1}$ & 0.194 & 0.070 \\
& $(0.152)$ & & $(0.160)$ & $(0.162)$ \\
$(\Delta \pi)_{\mathrm{t}-2}$ & -0.333 & $\pi_{\mathrm{t}-2}$ & -0.043 & 0.145 \\
& $(0.151)$ & & $(0.160)$ & $(0.159)$ \\
S.E.E. & 1.088 & S.E.E. & 2.398 & 3.413 \\
\hline
\end{tabular}

(Standard errors are in parentheses.) 
Table 2: Standard Errors of Inflation Forecasts

\begin{tabular}{lccc}
\hline & $1960-1999$ & $\begin{array}{c}1879-1914 \\
\text { Balke-Gordon }\end{array}$ & $\begin{array}{c}\text { 1879-1914 } \\
\text { Romer }\end{array}$ \\
\hline Multivariate & 0.837 & 2.097 & 3.261 \\
Univariate & 1.088 & 2.398 & 3.413 \\
Backward-Looking & 1.158 & 3.112 & 4.623 \\
\hline
\end{tabular}


Table 3: Alternative Phillips Curves - Semi-Annual Data, 1960-1999

(Dependent Vbl: $\pi_{t}$ )

\begin{tabular}{|c|c|c|c|}
\hline & Unrestricted & $\begin{array}{l}\text { Optimal Univariate } \\
\text { Expectations }\end{array}$ & $\begin{array}{l}\text { Backward-Looking } \\
\text { Expectations }\end{array}$ \\
\hline$\pi_{\mathrm{t}-1}$ & $\begin{array}{c}0.821 \\
(0.118)\end{array}$ & 1.080 & 1 \\
\hline$\pi_{\mathrm{t}-2}$ & $\begin{array}{c}0.123 \\
(0.152)\end{array}$ & -0.116 & 0 \\
\hline$\pi_{t-3}$ & $\begin{array}{l}-0.051 \\
(0.149)\end{array}$ & -0.152 & 0 \\
\hline$\pi_{\mathrm{t}-4}$ & $\begin{array}{c}0.009 \\
(0.148)\end{array}$ & 0.087 & 0 \\
\hline$\pi_{t-5}$ & $\begin{array}{c}0.097 \\
(0.111)\end{array}$ & 0.102 & 0 \\
\hline$y_{t}$ & $\begin{array}{c}0.166 \\
(0.104)\end{array}$ & 0.134 & 0.112 \\
\hline $\mathrm{y}_{\mathrm{t}-1}$ & $\begin{array}{c}0.037 \\
(0.164)\end{array}$ & 0.106 & 0.112 \\
\hline $\mathrm{y}_{\mathrm{t}-2}$ & $\begin{array}{l}0.095 \\
(0.147)\end{array}$ & -0.035 & 0 \\
\hline$y_{t-3}$ & $\begin{array}{l}-0.001 \\
(0.131)\end{array}$ & -0.003 & 0 \\
\hline$y_{t-4}$ & $\begin{array}{l}-0.045 \\
(0.091)\end{array}$ & 0.004 & 0 \\
\hline
\end{tabular}

(Standard errors are in parentheses.) 
Table 4: The Model with One-Period Prices: Univariate Expectations (Annual Data)

Part A: Coefficient Estimates

\begin{tabular}{cccc}
\hline $1960-1999$ & $\begin{array}{c}1879-1914 \\
\text { Balke-Gordon }\end{array}$ & $\begin{array}{c}1879-1914 \\
\text { Romer }\end{array}$ \\
\hline \multirow{2}{*}{$y_{\mathrm{t}}$} & 0.125 & 0.146 & 0.416 \\
$\mathrm{E}_{\mathrm{t}-1} \mathrm{y}_{\mathrm{t}}$ & $(0.081)$ & $(0.092)$ & $(0.202)$ \\
& 0.237 & -0.101 & -0.348 \\
& $(0.118)$ & $(0.159)$ & $(0.297)$ \\
\hline
\end{tabular}

(Standard errors are in parentheses.)

Part B: Phillips Curves

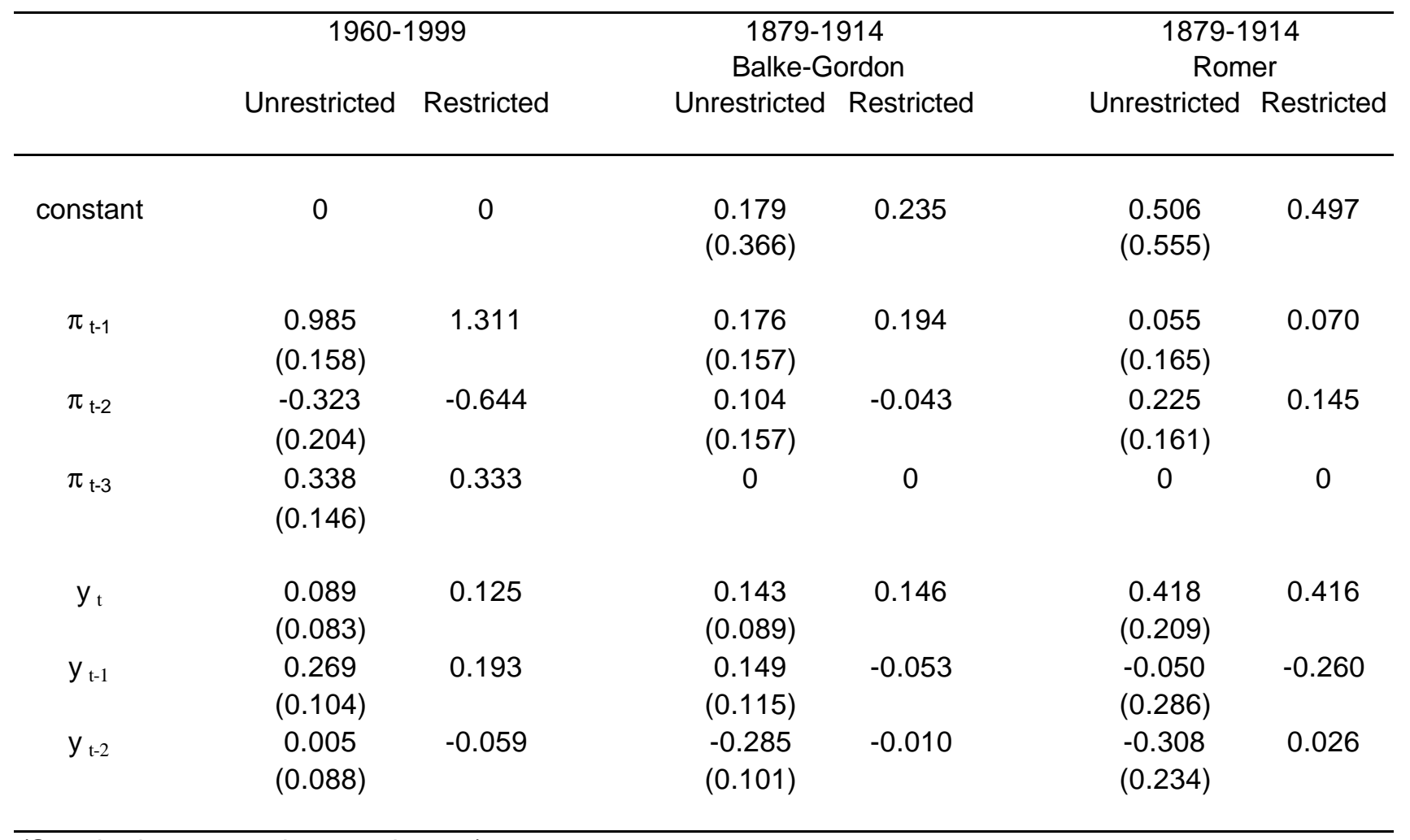

(Standard errors are in parentheses.) 
Table 5: The Model with One-Period Prices: Backward-Looking Expectations (Annual Data)

Part A: Coefficient Estimates

\begin{tabular}{cccc}
\hline $1960-1999$ & $\begin{array}{c}1879-1914 \\
\text { Balke-Gordon }\end{array}$ & $\begin{array}{c}1879-1914 \\
\text { Romer }\end{array}$ \\
\hline \multirow{2}{*}{$y_{\mathrm{t}}$} & 0.146 & 0.204 & 0.560 \\
& $(0.081)$ & $(0.122)$ & $(0.283)$ \\
$\mathrm{E}_{\mathrm{t}-1} \mathrm{y}_{\mathrm{t}}$ & 0.200 & -0.222 & -0.588 \\
& $(0.082)$ & $(0.125)$ & $(0.291)$ \\
\hline
\end{tabular}

(Standard errors are in parentheses.)

Part B: Phillips Curves

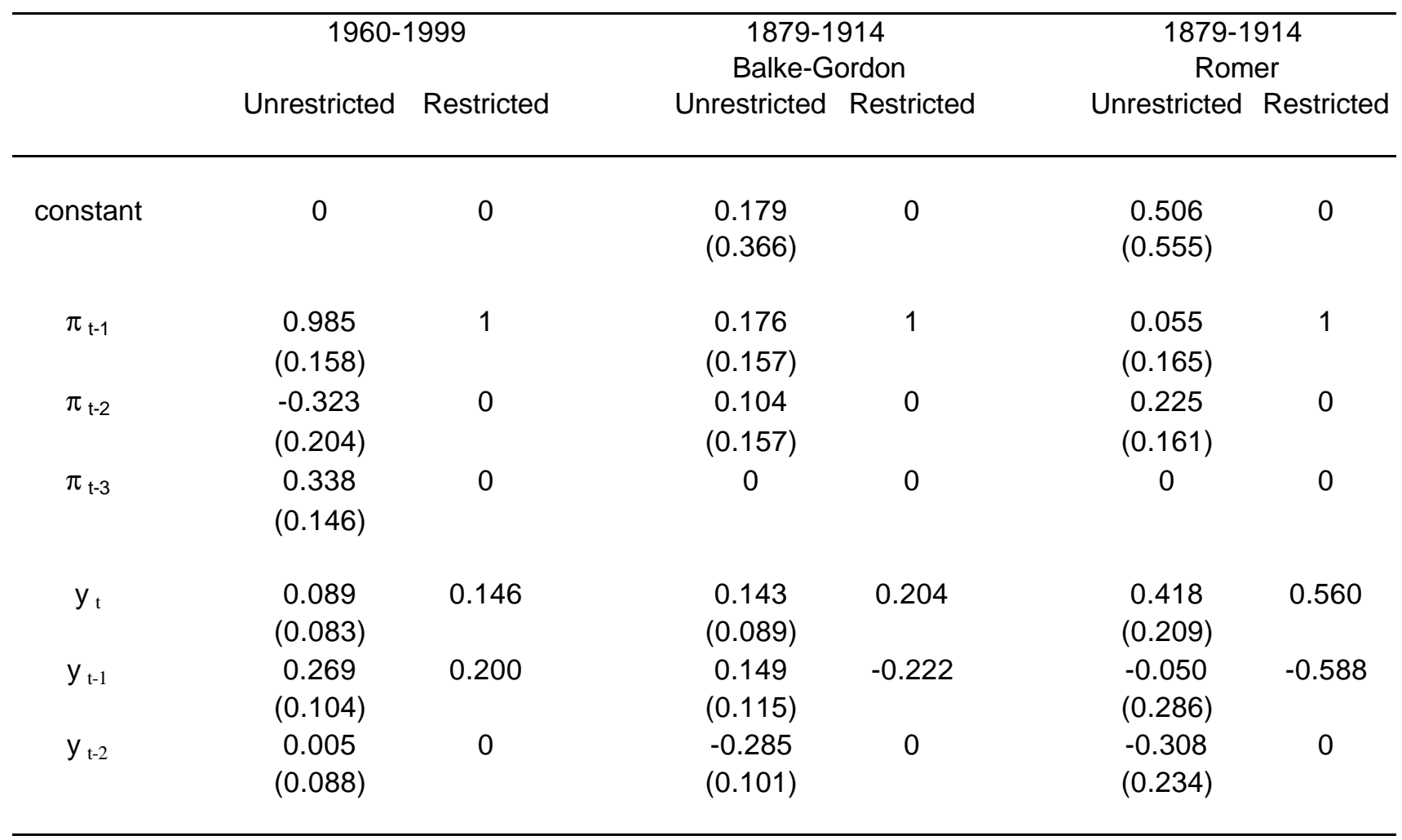

(Standard errors are in parentheses.) 
Figure 1: Impulse Response Functions - Optimal Univariate Expectations (Annual Data)
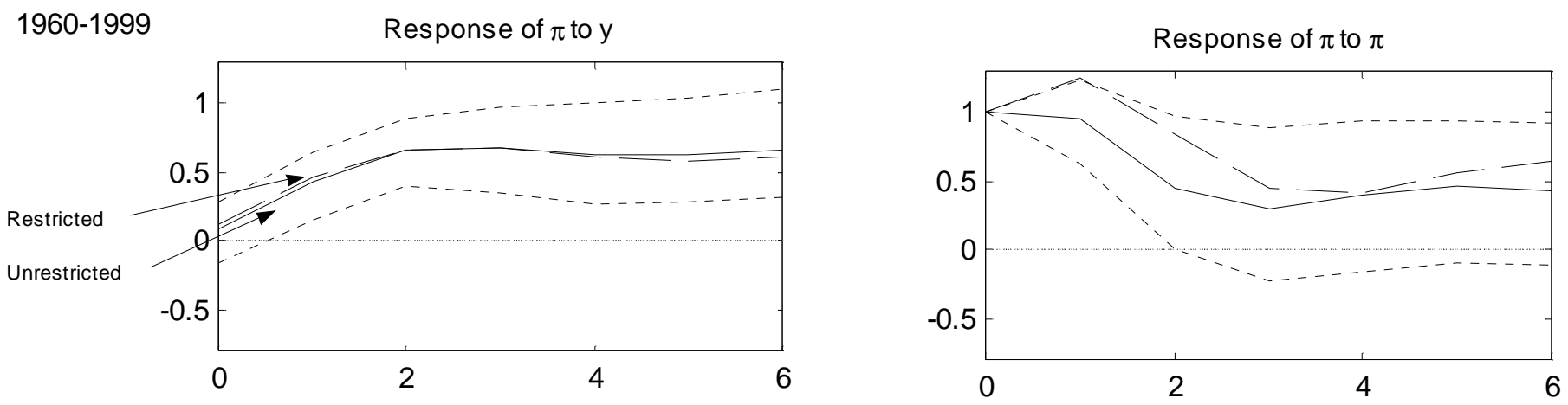

1879-1914 (Romer) Response of $\pi$ to $y$
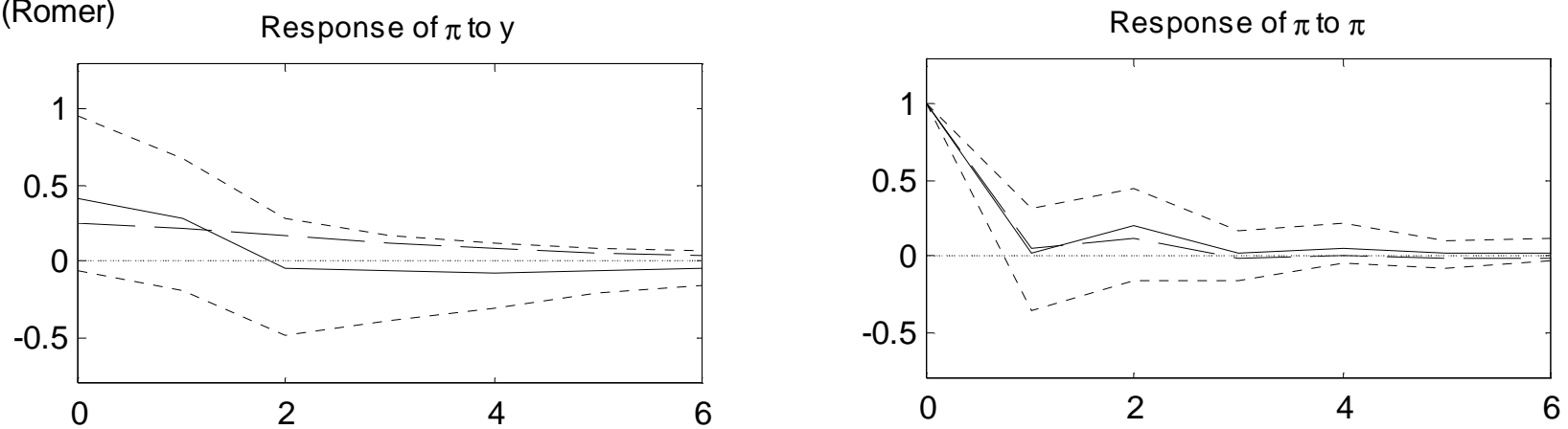

1879-1914 (Balke-Gordon)

Response of $\pi$ to $y$
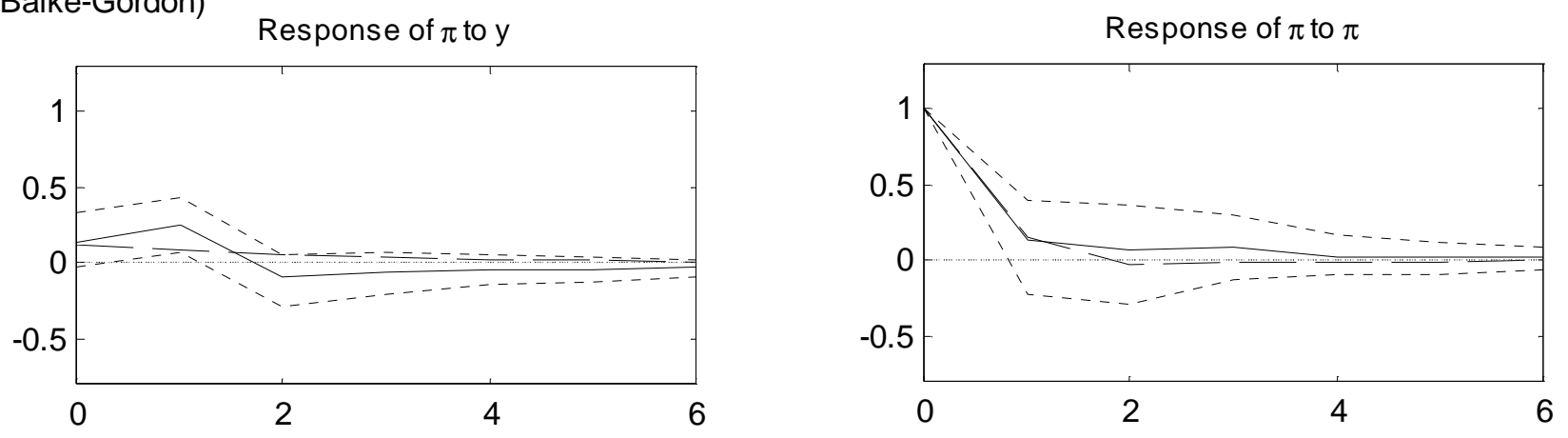
Figure 2: Impulse Response Functions - Backward-Looking Expectations

(Annual Data)
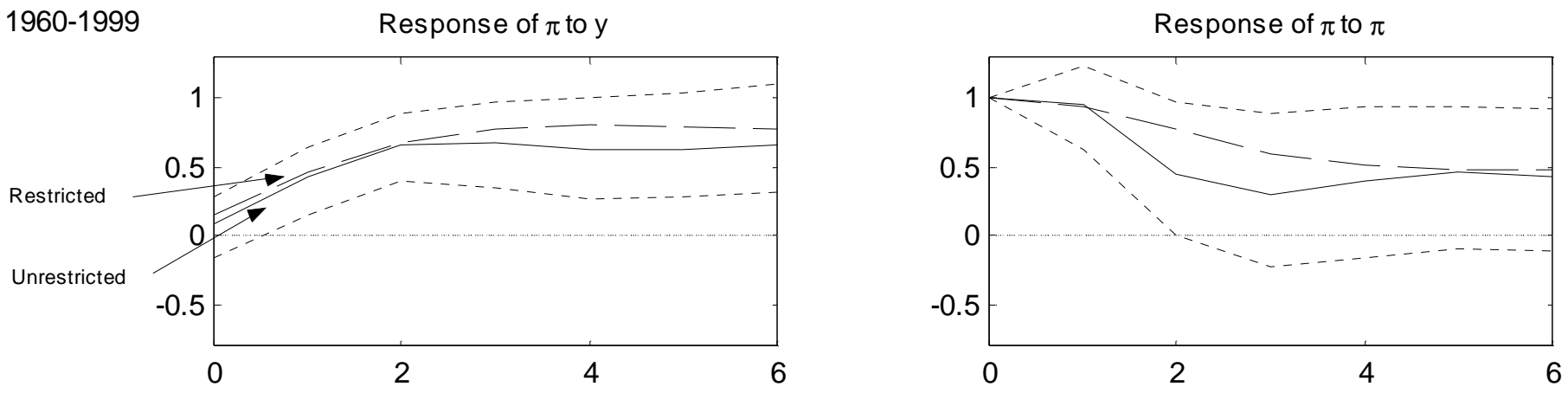

1879-1914 (Romer) Response of $\pi$ to $y$
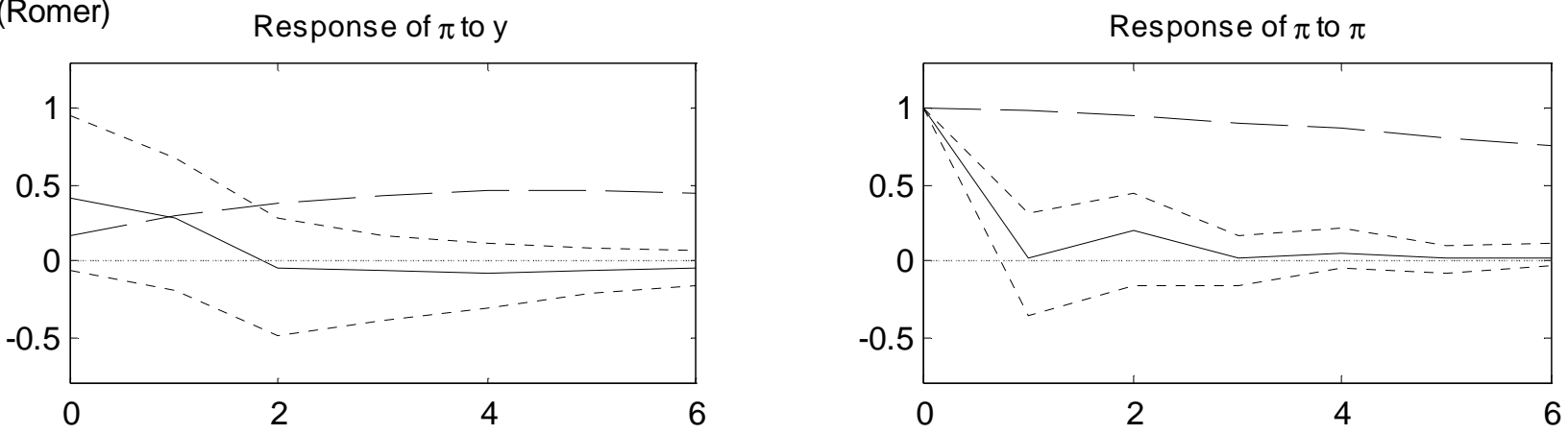

1879-1914 (Balke-Gordon)

Response of $\pi$ to $y$
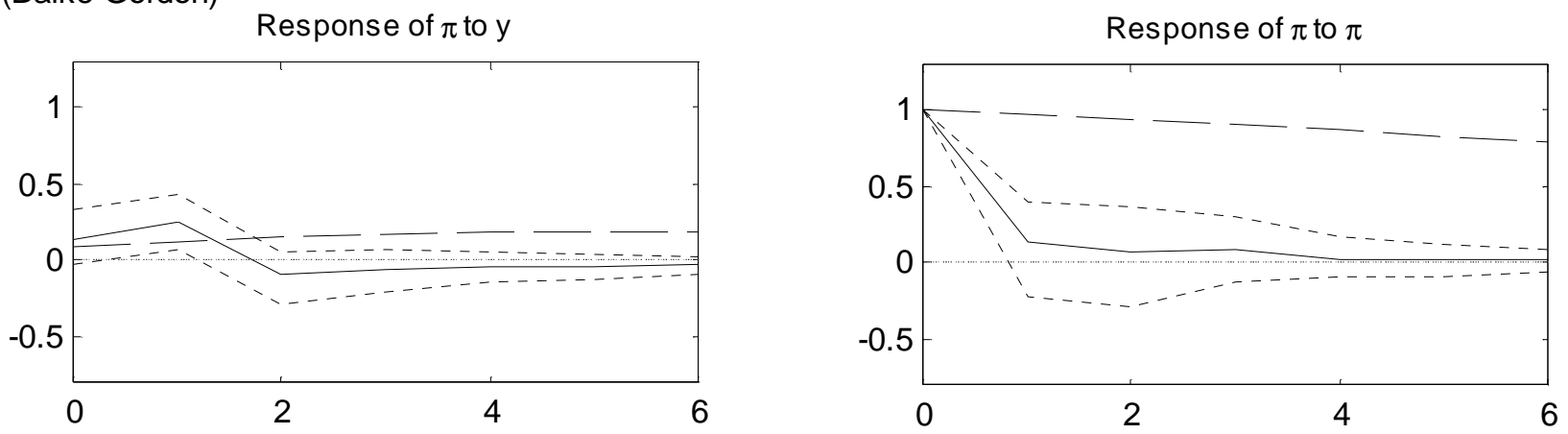